\title{
Clinical efficacy of ceramic versus resin- based composite endocrowns in Chinese adults: study protocol for a randomized controlled trial
}

Jilei Wang ${ }^{1+}$, Zhiting Ling ${ }^{1 \dagger}$, Ziting Zheng ${ }^{1}$, Chunqing Zheng ${ }^{1}$, Yawen Gai ${ }^{1}$, Yuting Zeng ${ }^{1}$, Xiaoxia Zhu', Liya Chen², Buling $\mathrm{Wu}^{1}$ and Wenjuan $\mathrm{Yan}^{1^{*}}$ (D)

\begin{abstract}
Background: Endocrown restoration is widely used to restore endodontically treated teeth. However, the clinical effects of different computer-aided design/computer-aided manufacturing (CAD/CAM) materials for endocrown restoration are not clear. The primary objective of this trial is to compare the clinical efficacy of resin-based bloc and ceramic endocrowns for restoring endodontically treated teeth.

Methods: The proposed resin-based bloc and ceramic endocrown assessment trial is a parallel group-designed randomized controlled trial. We will recruit 156 adults between 18 and 75 years old with a minimum of one such molar. The inclusion criteria were good oral hygiene habits, root apex of molar without evident damage, receipt of standard endodontic treatment, need for endocrown restoration, and only one endocrown restoration performed per patient. Patients participating in another study or those with systemic diseases, disabilities, or known allergies to used materials will be excluded. All patients will be randomized and restored with resin-based bloc and ceramic endocrown according to a random number table. Clinical evaluations will be performed at baseline and after treatment at 6, 12, and 24 months, in accordance with the modified Federation Dentaire Internationale (FDI) criteria, by two independent evaluators. The primary outcome is marginal adaptation; secondary outcomes include wear, tooth integrity, fracture of material and retention, marginal staining, and patient view. All data will be analyzed by an independent statistician. Signed rank-sum tests will be used for intragroup comparisons. Wilcoxon rank-sum tests will be used for intergroup comparisons. Hierarchical logistic regression will be used to adjust the baseline and other important indicators.

(Continued on next page)
\end{abstract}

\footnotetext{
* Correspondence: 645613053@qq.com

† Jilei Wang and Zhiting Ling contributed equally to this work.

'Department of Conservative and Endodontic Dentistry, Nanfang Hospital,

Southern Medical University, 1838 N Guangzhou Road, Guangzhou 510515,

China
}

Full list of author information is available at the end of the article

(c) The Author(s). 2020 Open Access This article is licensed under a Creative Commons Attribution 4.0 International License, which permits use, sharing, adaptation, distribution and reproduction in any medium or format, as long as you give appropriate credit to the original author(s) and the source, provide a link to the Creative Commons licence, and indicate if changes were made. The images or other third party material in this article are included in the article's Creative Commons licence, unless indicated otherwise in a credit line to the material. If material is not included in the article's Creative Commons licence and your intended use is not permitted by statutory regulation or exceeds the permitted use, you will need to obtain permission directly from the copyright holder. To view a copy of this licence, visit http://creativecommons.org/licenses/by/4.0/ The Creative Commons Public Domain Dedication waiver (http://creativecommons.org/publicdomain/zero/1.0/) applies to the data made available in this article, unless otherwise stated in a credit line to the data. 
(Continued from previous page)

Discussion: This study will investigate endocrowns of two CAD/CAM materials for endodontically treated molars. The results may help clinicians choose the better CAD/CAM material option and explain to patients the advantages and disadvantages of these two materials with evidence-based support. For patients, the results may lead to improvement in long-term restoration.

Trial registration: ClinicalTrials.gov NCT04033380. Registered on 24 July 2019

Keywords: Endocrown, CAD/CAM, Ceramic, Resin composite, Endodontically treated teeth, Randomized controlled trial

\section{Background}

Pulp disease and periapical disease are common oral diseases, and root canal therapy (RCT) is the most effective and ultimate treatment for these diseases [1]. In clinical practice, it is a major challenge to repair the tooth after RCT, since they will be more fragile than vital teeth [2]. If the restoration is not well done in time, the prognosis will decrease greatly, and tooth fracture is one of the most essential causes of treatment failure [3]. After the RCT, excessive removal of surrounding dentin tissue and pulps will cause damage to the overall structure of the tooth, the strength of the tooth will be reduced, and the tooth will lose the nutritional support of the pulp, eventually leading to tooth fracture [4]. Therefore, the endodontically treated teeth should be repaired in time [5]. Endocrowns, full crowns, and post-core crowns are often used to repair these teeth [6]. However, the full crown needs to cut a mass of dental tissues, which results in a significant reduction in the remaining healthy dental tissues [7]. Although post-core crown restoration can strengthen residual dental hard tissue and replace missing dental tissue, which provides the retaining force for the crown, post-core crown restoration can result in additional risks, such as canal perforation and root fracture [8]. Along with the increasing emphasis on minimally invasive trends and the development of adhesive dentistry, an increasing number of clinicians prefer to choose ways to retain more healthy dental tissues [9].

In recent years, the endocrown has been recognized as a new restoration method along with the advantage of minimally invasive treatment [10]. Endocrown is a kind of onlay that is composed of a butt plane and retainer deeply fixed into the internal walls of the pulp chamber [11]. Endocrowns are one-piece constructs that integrate the post, core, and crown to form a complete block prosthesis. In contrast to traditional internal fixation methods, endocrowns are anchored in the inner and margin of the pulp cavity, and the retentive effect better benefits from the macroscopic and microscopic mechanical retentions provided by the pulp cavity and adhesion [12]. Compared with full crown restoration, the endocrown loses less hard tissue, requires less clinical chair time, and the masticatory stress dispersion at the tooth/ prosthesis interface is more scientific [13]. Compared with post-core crown techniques, endocrown restoration is simplified because of the core-crown integrity. Furthermore, no post is needed, reducing the risk of root fracture [11]. In a systematic review of three clinical trials, endocrown restorations achieved $94-100 \%$ success, which was superior to that of traditional full crown restorations in the anterior teeth [14]. Endocrowns were also shown to restore severely damaged molars. The survival rate was excellent at $99.0 \%$ after $44.7 \pm 34.6$ months, which was superior to that documented in existing data on post- and core-based single crowns $[15,16]$.

The indications of endocrown include extensive dental defects, inadequate intermaxillary space, lack of the thickness requirements of ceramic materials, inability to use post-core crown or crown for restoration, and cases in which full crown restoration is prohibited due to anatomic variation of the posterior root [17]. We are currently processing a clinical trial on the effect of two marginal endocrown designs, and we found that the flat marginal design was easier to prepare than the $90^{\circ}$ shoulder endocrown was [18]. Therefore, the flat marginal form was used in this study (Fig. 1). At present, the fabrication of endocrowns is usually completed by chairside CAD/CAM [19]. CAD/CAM technology has the advantages of high efficiency and accuracy, significantly shortens the production time of restorations [20], and

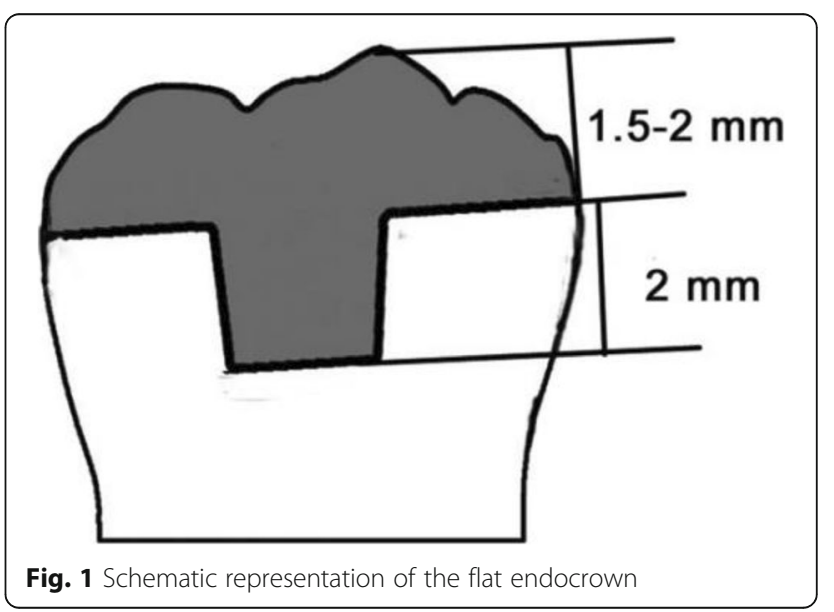


enables clinicians to provide high-quality esthetic restorations in a chairside manner. With the development of CAD/CAM systems, various CAD/CAM materials have been introduced [21]. It has been reported that the restorative effect of endocrowns is closely related to CAD/ CAM materials [22]. Leucite-reinforced lithium disilicate and zirconia-reinforced lithium silicate ceramics are thought to be the best choice with the advantages of esthetic and mechanical properties, translucency to natural teeth, good biocompatibility, anti-corrosion, anti-aging, and anti-abrasion [22, 23]. However, ceramic materials have high brittleness, and porcelain fracture frequently occurs and leads to restoration failure [24, 25]. Most ceramic restorations with chairside CAD/CAM require a second sintering. Studies have shown that the crystallization firing process results in a significant increase in the marginal gap size, likely due to shrinkage of the ceramic during the crystallization process $[26,27]$. The gap between the tooth and endocrown will reduce the compatibility between the restoration and the tooth and lead to the failure of the restoration.

More recently, ongoing research on biocompatible materials with physical and mechanical properties similar to those of natural tooth tissues has introduced a new generation of nanohybrid composite restorative materials (Grandio blocs, VOCO GmbH, Cuxhaven, Germany). The compositions of resin nanofillers allow the material to have a modulus of elasticity $(18.0 \mathrm{GPa})$ similar to that of dentin. The advantages of resin-based restorations are showing less crack propagation and providing better flexural strength than some CAD/CAM ceramics are $[28,29]$. Moreover, resin-based composites are easily cut, cause little damage to grinding burs, and are convenient for repair in the mouth when defects occur.

Because there are no sufficient clinical data to verify that endocrowns fabricated from different CAD/CAM materials are more suitable for the restoration of endodontically treated molars, the main aim of this trial was to compare the clinical efficacy of ceramic versus resinbased bloc endocrowns and to predict the clinical outcomes of these two restorations used for endodontically treated teeth.

\section{Objective}

The main objective is to compare the clinical efficacy of resin-based bloc and ceramic endocrowns in treating endodontically treated molars by assessing the marginal adaptation of restorations fabricated with a chairside CAD/CAM system (Dentsply Sirona, Bensheim, Germany). The minor objectives include evaluating the wear, radiographic examination, patient's view, and recurrence of caries between the study groups during the same period and looking for the prognostic and influencing factors of the related effects.

\section{Hypothesis}

Our working hypothesis is that the restorative effect of the resin-based bloc endocrown is superior to that of the ceramic endocrown.

\section{Methods \\ Trial design and blindness}

This is a randomization, parallel control, optimal design trial with two balanced parallel arms (see SPIRIT checklist, Additional file 1). A double-blinding strategy was designed in this trial. The patients and data analysts are blinded. Operators cannot be blinded because the surface treatment method of ceramic and resin endocrowns is different (in particular, the treatment of the intaglio surfaces of the restoration). It is not possible to blind evaluators because a dentist can easily recognize the material type.

\section{Block randomization}

The method of block randomization is adopted, the block length is set as 6, the number of random seeds is set as "20190811," and software SAS9.4 was used. All patients who gave consent for participation and who fulfilled the inclusion criteria were randomized. Randomization will be requested by the staff member from the Centre of Clinical Trials (Cen-Trial). After root canal treatment, the allocation of patients will be implemented according to the indication in the random number table. A nurse will call CenTrial and tell the doctors about the intervention, and then she will only write the treatment number in the patient's CRF file. Randomization will be conducted without any influence of the principal investigators, rates, or therapists.

\section{Participants}

The participants will be recruited from the Department of Conservative and Endodontic Dentistry in Nanfang Hospital, Southern Medical University. No special concomitant dental care or intervention is prohibited in participants after inclusion in the trial, except that concerning the included teeth.

\section{Inclusion criteria}

1. The patients are adults aged around $18-75$ years and have root apex of molar without evident damage and no root fracture.

2. Good oral hygiene habits.

3. Have a complete root canal therapy molar necessitating an endocrown restoration.

4. The patient has signed an informed consent form.

5. Only one endocrown restoration per patient is eligible. 


\section{Exclusion criteria}

1. Allergy to one of the materials used.

2. Poor oral hygiene, bruxism.

3. Severe periodontitis.

4. Pregnancy.

5. Incapable of self-care, mental illness or systemic diseases, and undergoing radiotherapy.

6. Unsuitable for the trial as deemed by the researchers.

\section{Eligibility criteria}

1. The dentist who works in the Division of Endodontics, Department of Stomatology, Nanfang Hospital, Southern Medical University, will perform the interventions.

2. The dentist who will perform the intervention must be licensed as a dentist and had an experience of CAD/CAM technique for at least 3 years.

\section{Dropout criteria}

1. Voluntary withdrawal from the trial by the patient.

2. Poor clinical compliance.

\section{Outcome measures}

Clinical evaluations will be conducted at baseline and after 6, 12, and 24 months of follow-up according to Federation Dentaire International (FDI) criteria by two independent evaluators (Table 1) [30-32]. A standardized training program must be finished by the two evaluators before the trial begins. The two evaluators were trained in the use of the criteria at Nanfang Hospital, SMU. During the first session, the rationale for the FDI criteria, the rating system, the coding system, and the record forms were explained and discussed. Ten restorations were then rated by the instructor to clinically illustrate the rating system. After the instructor explained the reason for assigning each rating, the trainees examined the same restorations. Each trainee was encouraged to explain his or her interpretation of each characteristic and thus his or her reasons for agreement or disagreement with ratings assigned by the instructor. Where disagreements occurred, the categories were again explained so that all examiners would invoke the same concepts when using the rating scales. If the two evaluators present inconsistent evaluations, a third evaluator will perform an evaluation, and the concurring evaluations from the evaluators will be used for analysis. The primary outcome, the marginal adaption of the restoration, will be measured based on the FDI criteria. When a case is evaluated with all items at level $\mathrm{A}$, the restoration is considered a success. When a case has one item
Table 1 Modified FDI criteria

\begin{tabular}{|c|c|c|}
\hline Category & Sub-categories & Grading \\
\hline \multirow{5}{*}{$\begin{array}{l}\text { a) } \\
\text { Functional } \\
\text { properties }\end{array}$} & 1. Marginal adaptation & \multirow{17}{*}{$\begin{array}{l}\text { A. Clinically excellent } \\
\text { B. Clinically good } \\
\text { C. Borderline quality/ } \\
\text { acceptance, repair } \\
\text { necessary/possible } \\
\text { D. Clinically unsatisfactory } \\
\text { (replacement necessary) }\end{array}$} \\
\hline & 2. Wear & \\
\hline & $\begin{array}{l}\text { 3. Proximal anatomical form } \\
\text { (contact point/food impact) }\end{array}$ & \\
\hline & 4. Radiographic examination & \\
\hline & 5. Patient's view & \\
\hline \multirow[t]{5}{*}{$\begin{array}{l}\text { b) Biological } \\
\text { properties }\end{array}$} & $\begin{array}{l}\text { 1. Recurrence of caries, } \\
\text { erosion, abfraction }\end{array}$ & \\
\hline & 2. Tooth integrity & \\
\hline & 3. Periodontal response & \\
\hline & 4. Adjacent mucosa & \\
\hline & 5. Oral and general health & \\
\hline \multirow{7}{*}{$\begin{array}{l}\text { c) Esthetic } \\
\text { properties }\end{array}$} & 1. Surface luster & \\
\hline & 2. Staining & \\
\hline & a. Surface & \\
\hline & b. Margin & \\
\hline & $\begin{array}{l}\text { 3. Color match and } \\
\text { translucency }\end{array}$ & \\
\hline & 4. Esthetic anatomical form & \\
\hline & $\begin{array}{l}\text { 5. Fracture of material and } \\
\text { retention }\end{array}$ & \\
\hline
\end{tabular}

The FDI criteria with their various categories and their grading (in italic: the revisions of 2010)

at level B and the other at a level no lower than level B, the restoration is considered acceptable, requiring further observation. If a case has any item at level $C$ or $D$, it is considered a failure. Secondary outcomes which include wear, proximal anatomical form, radiographic examination, patient's view, recurrence of caries, erosion, abfraction, tooth integrity, periodontal response, adjacent mucosa, oral and general health, surface luster, staining, color match and translucency, esthetic anatomical form, and fracture of material and retention will also be analyzed with FDI criteria.

\section{Primary outcome}

Marginal adaptation, FDI standard [2010], which has been defined as follows:

1. Harmonious outline, no gaps, no white or discolored lines $(\mathrm{A})$

2. Marginal gap $(<150 \mu \mathrm{m})$, white lines; small marginal fracture removable by polishing; slight ditching, slight step/flashes, minor irregularities (B)

3. Gap < $250 \mu \mathrm{m}$ not removable; several small marginal fractures; major irregularities, ditching or flash, steps (C) 
4. Gap $>250 \mu \mathrm{m}$ or dentine/base exposed; severe ditching or marginal fractures; larger irregularities or steps (repair necessary) (D)

\section{Secondary outcome}

Wear:

1. Physiological wear equivalent of enamel (A)

2. Normal wear only slightly different from that to enamel (B)

3. Different wear rate than enamel but within the biological variation $(C)$

4. Wear considerably exceeds normal enamel, or occlusal contact points are lost (D)

As for the evaluation of the patient's view, the following questionnaire will be reviewed:

1. Entirely satisfied with esthetics and function (A)

2. Satisfied with esthetics and function with minor roughness (B)

3. Minor criticism but no adverse clinical effects (B)

a. Esthetic shortcomings

b. Some lack of chewing comfort

c. Unpleasant treatment procedure

4. Desire for improvement: esthetics, function, tongue irritation $(C)$

5. Completely dissatisfied and/or adverse effects, including pain (D)

\section{Sample size and recruitment procedures}

The main evaluation index was the marginal adaptation of the restoration. In this study, the proportions of grades A (clinically excellent), B (clinically good), C (borderline quality/acceptance, repair necessary/possible), and D (clinically unsatisfactory, replacement necessary) in the experimental group are expected to be $60 \%, 30 \%$, $8 \%$, and $2 \%$, respectively. The proportions of grades $\mathrm{A}$, $\mathrm{B}, \mathrm{C}$, and $\mathrm{D}$ in the control group are expected to be $40 \%$, $30 \%, 20 \%$, and $10 \%$, respectively. After a bilateral inspection level of 0.05 was set and the power of the test was set to no lower than $80 \%$, nQuery 8.0 software was applied to calculate the sample size, in which 124 patients (62 for each group) were recruited. Considering that $20 \%$ of patients might drop out in the follow-up, the final recruitment sample size of this trial would be 156 patients (78 in each group).

The participants will be recruited from the Department of Conservative and Endodontic Dentistry in Nanfang Hospital, Southern Medical University. There are many patients with root canal treatment in this department each year. Approximately 20-30 endocrown restorations have been fabricated by CAD/CAM in this hospital each month according to the data of last year.
Therefore, the achievement of adequate participants is feasible in 2 years. We promise compensation to the patients who participate in the study. Every half a year, all the participants will receive free dental care including teeth cleaning and X-ray examination and oral examination. Every 3 months, a phone call follow-up will be executed to evaluate participants' general condition. The traffic fee for each visit will be compensated.

\section{The intervention group and control group}

All participants will be randomly allocated into two groups. One group will receive a Vita suprinity endocrown, and the other group will receive with Grandio bloc endocrown (Table 2). Randomization will be performed in accordance with a random list of numbers generated by the Department of Biomedical Statistics of Southern Medical University. The 5 operators are endodontists from the Department of Conservative and Endodontic Dentistry in Nanfang Hospital, Southern Medical University, and all of them will be eligible for inclusion and will receive standardized training in endocrown restoration as previously described before the study begins [18]. The chairside CAD/CAM endocrown will be designed and fabricated by the same technician. The number of cases assigned to each dentist is approximately 30 . Another two dentists will serve as evaluators and will be responsible for observing the restorations and collecting data during follow-up.

\section{Data collection}

The data will be collected from a case report form (CRF) that records all information at baseline and follow-up. The data will be kept anonymous. The CRF includes demographic data, oral habits, medical history, follow-up data, and adverse events. Patients will be identified by the alphabetical order of their full name on the form. The data will be input twice into the database by designated operators and checked by a data manager. The CRF form (hard copy) will be locked in a separated safety box. The database will be submitted and stored in Cen-Trial. To protect the privacy of patients, the patients will be registered with their first letters of their full name at filling the form.

\section{Statistical methods \\ Basic principles}

The nQuery 8.0 statistical software will be used for statistical analysis. The data will be analyzed by an independent statistician. All statistical tests are two-tailed. A $P$ value of less than 0.05 will be the level of significance, and $95 \%$ confidence intervals will be calculated. Parametric methods will be considered first. Data that do not meet or cannot be transformed to meet parametric assumptions will be analyzed by non-parametric methods. 
Table 2 SPIRIT (Standard Protocol Items: Recommendations for Interventional Trials)

\begin{tabular}{|c|c|c|c|c|c|}
\hline TIMEPOINT & Pre-treatment & Post-treatment & $\begin{array}{l}\text { 6-month } \\
\text { follow-up }\end{array}$ & $\begin{array}{l}\text { 12-month } \\
\text { follow-up }\end{array}$ & $\begin{array}{l}\text { 24-month } \\
\text { follow-up }\end{array}$ \\
\hline \multicolumn{6}{|l|}{ ENROLMENT: } \\
\hline Eligibility screen & $x$ & & & & \\
\hline Informed consent & $x$ & & & & \\
\hline Baseline data collection & $x$ & & & & \\
\hline Randomize subjects & $x$ & & & & \\
\hline Allocation & $x$ & & & & \\
\hline \multicolumn{6}{|l|}{ INTERVENTIONS: } \\
\hline \multicolumn{6}{|l|}{ Grandio bloc } \\
\hline \multicolumn{6}{|l|}{ Vita suprinity } \\
\hline \multicolumn{6}{|l|}{ ASSESSMENTS: } \\
\hline Primary outcome & & $x$ & $x$ & $x$ & $x$ \\
\hline Secondary outcomes & & $x$ & $x$ & $x$ & $x$ \\
\hline
\end{tabular}

\section{Primary outcome analysis}

Signed rank-sum tests will be used for intragroup comparisons, and Wilcoxon rank-sum tests will be used for intergroup comparisons. Hierarchical logistic regression will be used to adjust the baseline and other important indicators.

\section{Secondary outcome analysis}

For intragroup comparisons, paired $t$ tests or signed rank-sum tests will be used for quantitative variables, and McNemar tests will be used for qualitative variables.

For intergroup comparisons, quantitative variables will be analyzed by two-sample $t$ tests (two groups) or by non-parametric methods. Qualitative variables will be analyzed by Pearson's chi-square tests. Rank variables were tested by Wilcoxon rank-sum tests.

\section{Data monitoring}

The DMC consists of the Department of Biomedical Statistics, Southern Medical University, and it is mainly responsible for data management and statistical analysis. It is independent of the sponsor and has no competing interests.

\section{Harms}

In our study, an adverse event will be defined as any untoward medical occurrence in a subject without regard to the possibility of a causal relationship. The adverse events include the materials in the restoration process causing allergic reactions and the prosthesis falling off, leading to aspiration. Any serious adverse events occurring during the course of the test shall be reported to the medical ethics committee of the unit and the applicant immediately, and the "report form of serious adverse events" will be completed. If it is a serious adverse reaction, it will be reported to the state drug supervision and administration within $24 \mathrm{~h}$.

\section{Auditing}

The frequency of audit is once a year. The project organization will review the test process and make a comprehensive evaluation. Eliminate funding for lower ranked projects. The process will be independent from investigators and the sponsor.

\section{Discussion}

In this trial, the FDI criteria will be used to evaluate the quality of restorations. The proposed FDI criteria allow for the classification of the evaluation of dental restorations according to functional, biological, and esthetic categories. Compared to the USPHS criteria, a higher number of scores ( 1 to 5 ) were reported to make it easier to discern potential differences in the quality of restorations [33], which increases the overall quality of assessments. Moreover, the FDI criteria can be used to standardize clinical judgment of restorations, allowing for comparisons with all other studies.

We will test two types of CAD/CAM materials that are commonly used in clinical practice. Grandio blocs contain $86 \% \mathrm{w} / \mathrm{w}$ inorganic fillers in a polymer matrix for enhanced strength and excellent wear resistance. With the advantage of dentin-like elasticity modulus, the GR endocrown (composite resin) could achieve a more approximate monoblock structure and dissipate more energy under the same loading, which may have the highest fracture resistance. Vita suprinity (ceramic) has a significant fracture resistance value $(1784 \mathrm{~N})$ and more wear resistance than other CAD/CAM ceramic materials have, 
causing the addition of zirconia to increase its strength $[22,34]$. However, the potential for brittle catastrophic fracture and excessive wear on opposing natural teeth are considered the predominant deficiencies $[35,36]$. The results of this randomized control trial will allow for advancement in the recommendations and will be beneficial for the patient, the practitioner, and the researcher.

\section{Trial status}

The protocol version number is NFEC-2017-141 and approved on Sep. 7, 2017. This trial is in the process of recruiting participants. The trial recruiting has started on Jul. 26, 2019, and the recruitment will be completed in 2 years.

\section{Supplementary information}

Supplementary information accompanies this paper at https://doi.org/10. 1186/s13063-020-04506-9.

Additional file 1. SPIRIT (Standard Protocol Items: Recommendations for Interventional Trials) 2013 Checklist: Recommended items to address in a clinical trial protocol and related documents.

\section{Abbreviations \\ CAD/CAM: Computer-aided design/computer-aided manufacture; CRF: Case report form; RCT: Root canal treatment; FDI: Federation Dentaire Internationale \\ Dissemination plans \\ Results will be communicated to relevant groups via conferences, publications, reporting results in databases, data sharing arrangements, WeChat, and social media or through the sponsor.}

\begin{abstract}
Authors' contributions
Wenjuan Yan and Buling Wu developed and improved the trial design. Jilei Wang and Zhiting Ling drafted the manuscript, and Wenjuan Yan carefully revised and edited it. Yawen Gai and Yuting Zeng recruited the participants. Ziting Zheng and Chunqing Zheng conducted patient follow-up investigation. Xiaoxia Zhu carried outpatient care cooperation work, and Liya Chen designed the random number table. All authors read and approved the final manuscript. The datasets analyzed during the current study are available from the corresponding author on reasonable request.
\end{abstract}

\section{Funding}

This trial is funded by grants from the Clinical Research Program of Nanfang Hospital, Southern Medical University (2018CR018); Clinical Research Startup Program of Southern Medical University by High-level University Construction Funding of Guangdong Provincial Department of Education (LC2016PY023).

\section{Availability of data and materials}

Any data required to support the protocol can be supplied on request.

\section{Ethics approval and consent to participate}

The trial has been approved by the Medical Ethics Committee of Nanfang Hospital, Southern Medical University. This protocol has been reviewed and approved by the sponsor and the ethical committees. Subsequent to initial review and approval, the sponsor and the ethical committees will review the protocol at least annually. The investigator will make safety and progress reports to the ethical committees at least annually and within 3 months of study termination or completion at her site. Any amendments to the protocol will be reviewed and approved by the ethics committee and funding support departments.

Trained researchers will introduce the trial to patients. Patients will also receive information sheets. Researchers will discuss the trial with patients. Researchers will obtain written consent from patients willing to participate in the trial. On the consent form, participants will be asked if they agree to use of their data should they choose to withdraw from the trial. Participants will also be asked for permission for the research team to share relevant data with people from the Universities taking part in the research or from regulatory authorities, where relevant. This trial does not involve collecting biological specimens for storage.

\section{Consent for publication}

This is available from the corresponding author on request.

\section{Competing interests}

All academic conferences and research activities related to this study will be reimbursed. No other competing interests.

\section{Author details}

'Department of Conservative and Endodontic Dentistry, Nanfang Hospital, Southern Medical University, 1838 N Guangzhou Road, Guangzhou 510515, China. ${ }^{2}$ The Statistics Room of Nanfang Hospital, Southern Medical University, Guangzhou, China.

Received: 22 November 2019 Accepted: 12 June 2020

Published online: 22 June 2020

\section{References}

1. Soh JA, Sheriff SO, Ramar NA, Pulikkotil SJ, Nagendrababu V, Neelakantan P, Amalraj FD. Effect of root canal debridement on inflammatory cytokine levels. Aust Endod J. 2019;45:171.

2. Mondelli J, Rizzante FAP, Valera FB, Roperto R, Mondelli RFL, Furuse AY. Assessment of a conservative approach for restoration of extensively destroyed posterior teeth. J Appl Oral Sci. 2019;27:e20180631.

3. McCracken MS, Louis DR, Litaker MS, Minye HM, Mungia R, Gordan W, Marshall DG, Gilbert GH. Treatment recommendations for single-unit crowns: findings from the National Dental Practice-Based Research Network. J Am Dent Assoc. 2016;147:882.

4. Zelic K, Vukicevic A, Jovicic G, Aleksandrovic S, Filipovic N, Djuric M. Mechanical weakening of devitalized teeth: three-dimensional finite element analysis and prediction of tooth fracture. Int Endod J. 2015:48:850

5. Prati C, Pirani C, Zamparini F, Gatto MR, Gandolfi MG. A 20-year historical prospective cohort study of root canal treatments. A multilevel analysis. Int Endod J. 2018;51:955.

6. Sequeira-Byron P, Fedorowicz Z, Carter B, Nasser M, Alrowaili EF. Single crowns versus conventional fillings for the restoration of root-filled teeth. Cochrane Database Syst Rev. 2015:CD009109.

7. Murphy F, McDonald A, Petrie A, Palmer G, Setchell D. Coronal tooth structure in root-treated teeth prepared for complete and partial coverage restorations. J Oral Rehabil. 2009;36:451.

8. Rayyan MR, Alauti RY, Abanmy MA, AlReshaid RM, Bin Ahmad HA. Endocrowns versus post-core retained crowns for restoration of compromised mandibular molars: an in vitro study. Int J Comput Dent. 2019;22(1):39-44.

9. Martins B, Silva E, Ferreira D, Reis KR, Fidalgo T. Longevity of defective direct restorations treated by minimally invasive techniques or complete replacement in permanent teeth: a systematic review. J Dent. 2018;78:22.

10. Lin $C$, Chang $Y, P a$ C. Estimation of the risk of failure for an endodontically treated maxillary premolar with MODP preparation and CAD/CAM ceramic restorations. J Endodont. 2009;35:1391.

11. Biacchi GR, Basting RT. Comparison of fracture strength of endocrowns and glass fiber post-retained conventional crowns. Oper Dent. 2012;37:130.

12. Dartora NR, de Conto FM, Moris I, Brazao EH, Spazin AO, Sousa-Neto MD, Silva-Sousa YT, Gomes EA. Effect of intracoronal depth of teeth restored with endocrowns on fracture resistance: in vitro and 3-dimensional finite element analysis. J Endod. 2018;44:1179.

13. El GW, Ozcan M, Silwadi M, Salameh Z. Fracture resistance and failure modes of endocrowns manufactured with different CAD/CAM materials under axial and lateral loading. J Esthet Restor Dent. 2019;31:378.

14. Sedrez-Porto JA, Rosa WL, Da SA, Munchow EA, Pereira-Cenci T. Endocrown restorations: a systematic review and meta-analysis. J Dent. 2016;52:8.

15. Belleflamme MM, Geerts SO, Louwette MM, Grenade CF, Vanheusden AJ, Mainjot AK. No post-no core approach to restore severely damaged posterior teeth: an up to 10-year retrospective study of documented endocrown cases. J Dent. 2017;63:1. 
16. Schmitter M, Hamadi K, Rammelsberg P. Survival of two post systems-fiveyear results of a randomized clinical trial. Quintessence Int. 2011;42:843.

17. Govare N, Contrepois M. Endocrowns: a systematic review. J Prosthet Dent. 2019; 123:411-8.

18. Sun J, Ruan W, He J, Lin X, Ci B, Yin S, Yan W. Clinical efficacy of different marginal forms of endocrowns: study protocol for a randomized controlled trial. Trials. 2019;20:454.

19. Blatz MB, Conejo J. The current state of chairside digital dentistry and materials. Dent Clin N Am. 2019;63:175.

20. Zhang Y, Tian J, Wei D, Di P, Lin Y. Quantitative clinical adjustment analysis of posterior single implant crown in a chairside digital workflow: a randomized controlled trial. Clin Oral Implants Res. 2019;30:1059-66.

21. Ramirez-Sebastia A, Bortolotto T, Roig M, Krejci I. Composite vs ceramic computer-aided design/computer-assisted manufacturing crowns in endodontically treated teeth: analysis of marginal adaptation. Oper Dent 2013;38:663.

22. Ghajghouj O, Tasar-Faruk S. Evaluation of fracture resistance and microleakage of endocrowns with different intracoronal depths and restorative materials luted with various resin cements. Materials (Basel). 2019;12(16):2528

23. Mendonca LM, Ramalho IS, Lima L, Pires LA, Pegoraro TA, Pegoraro LF. Influence of the composition and shades of ceramics on light transmission and degree of conversion of dual-cured resin cements. J Appl Oral Sci. 2019;27:e20180351.

24. Sedrez-Porto JA, Munchow EA, Valente LL, Cenci MS, Pereira-Cenci T. New material perspective for endocrown restorations: effects on mechanical performance and fracture behavior. Braz Oral Res. 2019;33:e12.

25. Hampe R, Theelke B, Lumkemann N, Eichberger M, Stawarczyk B. Fracture toughness analysis of ceramic and resin composite CAD/CAM material. Oper Dent. 2019:44:E190.

26. Gold SA, Ferracane IL, Da CJ. Effect of crystallization firing on marginal gap of CAD/CAM fabricated lithium disilicate crowns. J Prosthodont. 2018;27:63.

27. Riquieri H, Monteiro JB, Viegas DC, Campos T, de Melo RM, de Siqueira FASG. Impact of crystallization firing process on the microstructure and flexural strength of zirconia-reinforced lithium silicate glass-ceramics. Dent Mater. 2018;34:1483.

28. Pfeilschifter $M$, Preis $V$, Behr M, Rosentritt M. Edge strength of CAD/CAM materials. J Dent. 2018;74:95.

29. Colombo M, Poggio C, Lasagna A, Chiesa M, Scribante A. Vickers microhardness of new restorative CAD/CAM dental materials: evaluation and comparison after exposure to acidic drink. Materials (Basel). 2019;12(8):1246.

30. Hickel R, Roulet JF, Bayne S, Heintze SD, Mjor IA, Peters M, Rousson V, Randall R, Schmalz G, Tyas M, Vanherle G. Recommendations for conducting controlled clinical studies of dental restorative materials. Clin Oral Investig. 2007;11:5.

31. Hickel R, Peschke A, Tyas M, Mjor I, Bayne S, Peters M, Hiller KA, Randall R, Vanherle G, Heintze SD. FDI World Dental Federation: clinical criteria for the evaluation of direct and indirect restorations-update and clinical examples. Clin Oral Investig. 2010;14:349.

32. Marquillier T, Domejean S, Le Clerc J, Chemla F, Gritsch K, Maurin JC, Millet $\mathrm{P}$, Perard M, Grosgogeat B, Dursun E. The use of FDI criteria in clinical trials on direct dental restorations: a scoping review. J Dent. 2018;68:1.

33. Coelho-De-Souza FH, Camargo JC, Beskow T, Balestrin MD, Klein-Junior CA, Demarco FF. A randomized double-blind clinical trial of posterior composite restorations with or without bevel: 1-year follow-up. J Appl Oral Sci. 2012;20:174.

34. Tribst J, Alves L, Piva A, Melo RM, Borges A, Paes-Junior T, Bottino MA. Reinforced glass-ceramics: parametric inspection of three-dimensional wear and volumetric loss after chewing simulation. Braz Dent J. 2019;30:505.

35. Zhi L. Bortolotto T, Krejci I. Comparative in vitro wear resistance of CAD/ CAM composite resin and ceramic materials. J Prosthet Dent. 2016;115:199.

36. Lawson NC, Bansal R, Burgess JO. Wear, strength, modulus and hardness of CAD/CAM restorative materials. Dent Mater. 2016;32:e275.

\section{Publisher's Note}

Springer Nature remains neutral with regard to jurisdictional claims in published maps and institutional affiliations.

\section{Ready to submit your research? Choose BMC and benefit from:}

- fast, convenient online submission

- thorough peer review by experienced researchers in your field

- rapid publication on acceptance

- support for research data, including large and complex data types

- gold Open Access which fosters wider collaboration and increased citations

- maximum visibility for your research: over $100 \mathrm{M}$ website views per year

At BMC, research is always in progress.

Learn more biomedcentral.com/submissions 